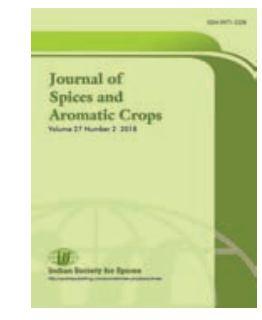

\title{
Mycotoxigenic Aspergillus flavus from ginger and turmeric consumed in the Niger Delta Region of Nigeria
}

\author{
V C Okereke* \& M I Godwin-Egein \\ Department of Crop and Soil Science, University of Port Harcourt \\ Choba, PMB 5323, Port Harcourt, Nigeria. \\ *E-mail: chykeoky@yahoo.com
}

Received 31 March 2018; Revised 23 June 2018; Accepted 25 October 2018

\begin{abstract}
Ginger and turmeric sold in the open markets and retail outlets in southern Nigeria were sampled between April and August, 2017. This period coincided with the first bimodal peak of the rainy season of the 2017 cropping season. Malt extract agar (MEA) and Dichloran 18\% glycerol (DG18) media were used to isolate fungi from samples with or without surface sterilisation. Aspergillus spp isolated were examined for the production of orange-yellow pigmentation and blue fluorescence on the reverse side of the plate on CAM under UV light. Aflatoxin production by Aspergillus flavus on yeast extract sucrose (YES) was verified quantitatively using High Performance Liquid Chromatography (HPLC). Data showed that Fusarium, Penicillium and Aspergillus spp were the dominant fungal flora. Toxigenic isolates of A. flavus; $\mathrm{AFg}_{1}, \mathrm{AFg}_{3^{\prime}} \mathrm{AFt}_{1^{\prime}}$ and $\mathrm{AFt}_{3}$ produced both orange-yellow pigmentation and blue fluorescence on CAM. The production of $\mathrm{AFB}_{1}$ and $\mathrm{AFB}_{2}$ on YES medium was confirmed using HPLC. The occurrence of toxigenic fungi indicates that there is a potential risk of mycotoxin contamination in ginger and turmeric consumed in southern Nigeria and problems can arise from contamination with aflatoxins.
\end{abstract}

Keywords: aflatoxin, Aspergillus, ginger, mycotoxin, toxigenic, turmeric

\section{Introduction}

Ginger and turmeric are among the commonly used spices in the world. India is the largest producer, consumer and exporter in the world and contributes more than $50 \%$ of the world trade (Chaudhary et al. 2006). Other major producers are China, Nepal, Nigeria and Indonesia. These spices are obtained from underground rhizomes, and have medicinal properties (Olojede et al. 2009; Karim et al. 2010; Singletary, 2010) and also used widely for other household purposes (Sherman \& Billing 1999). Farmers' interest on large scale production of these crops the world over have been stimulated by recent studies on the efficacy of these spices on the treatment of health conditions such as 
diabetics, nausea, vomiting, high cholesterol, high blood pressure and inflammation (Chen et al. 2007; Ernest \& Pittler, 2008; Kim et al. 2008). The Nigerian government, research institutions and many private organisations are now investing in the cultivation and marketing of these products and this has increased its trade in most Nigerian markets. In Nigeria, for instance a sizable proportion of these products are lost due to fungal contamination during the journey from the north where they are largely produced to the southern parts where they are largely consumed. Handling, processing and storage have not been the best. The way these products are displayed in Nigerian markets encourages the growth of moulds and thus mycotoxin contamination is imminent. The rain forest ecological zone of Nigeria, which is the dominant ecology in the south characterized by high temperature and humidity encourage the growth of toxigenic mould and mycotoxin production (Marin et al. 1998; Schmidt-Heydt et al. 2010).

Mycotoxins are secondary metabolites of fungi produced and secreted into a wide range of foods and food products. The most common fungal contaminants of spices belong to Aspergillus, Penicillium and Fusarium genera and some species of these genera have the ability to produce different mycotoxins such as aflatoxins (AFs) (Magan et al. 2011), ochratoxin (OTA) (Sultan \& Magan 2010), citrinin (CTN) (Jeswal \& Kumar 2014; 2015) and deoxynivalenol (DON) (Nicholson et al. 2007). Aflatoxins are secondary metabolites produced by the Aspergillus genus and they are carcinogenic (Liu \& Wu, 2010). Aflatoxin contamination of food products has received serious attention because $A F B$ is classified as a Class $1 \mathrm{~A}$ carcinogen and the EU and many countries of the world have strict maximum levels of contamination (European Commission, 2006; 2010). In 2017, WHO identified aflatoxins (Class 1A carcinogens) as responsible for causing stunting of children in lower middle income countries, especially in parts of sub-Saharan Africa. The consumption of ginger and turmeric has increased steadily, especially in Nigeria because of their health benefits and industrial uses (Bakht et al. 2012; 2013). Therefore, understanding the status of mycotoxin producing fungal species especially in the humid tropics where the environmental conditions are most favourable is very important. Scanty information is available on the incidence of mycotoxigenic moulds in southern Nigeria which has a high rate of consumption of these products, and this has necessitated the need for this study. The objectives of the study were to identify the fungal flora associated with commonly marketed ginger and turmeric in southern Nigeria and to ascertain the occurrence of aflatoxin producing isolates of Aspergillus spp from these products.

\section{Materials and methods}

\section{Sampling}

Ginger and turmeric samples were sourced from different randomly-selected retail outlets including supermarkets, grocery stores, open market stalls and wholesale outlets in Abia, Akwa Ibom, Bayelsa, Cross River, Imo and Rivers States in the Niger Delta region of Nigeria. The Niger River is located in the Gulf of Guinea in Nigeria with latitude $5^{\circ} 19^{\prime} 20.40^{\prime \prime} \mathrm{N}$ and longitude: $6^{\circ}$ $28^{\prime} 8.99 "$ E. Sampling was done between April August which coincides with the first bimodal peak of the rainy season of the 2017 cropping season. A total of 400 samples were collected (240 ginger and 260 turmeric), air dried appropriately and stored in sterile cellophane bags at $4^{\circ} \mathrm{C}$.

\section{Fungal isolation and identification}

Two media [Malt extract agar (MEA) and Dichloran 18\% glycerol media (DG18; both Oxoid Ltd., UK)] were used to plate $2 \mathrm{~mm}$ ginger and turmeric pieces ( 5 pieces per Petri plate $x 10$ plates per medium) either unsterilized or after surface sterilisation (to compare the level of secondary contaminants) using $1 \%$ sodium hypochlorite for $1 \mathrm{~min}$ followed by rinsing in sterile water for 30 seconds. The samples were dried on filter paper. The pieces were placed equidistant on the media using a sterile forceps and incubated at $25 \pm 2^{\circ} \mathrm{C}$ for 10 days. Colony forming units of fungi were sub-cultured until pure cultures were isolated. The identification of the fungal flora was realized microscopically, based on the morphology of spores and conidial, colony growth and with reference to Pitt \& Hocking (2009). Aspergillus flavus strain (NRRL 3357) was also used for comparison. Fungal colonies were 
counted and recorded and separated into species. The total number of fungal colonies grown on the same set of plates was recorded. Percentage of occurrence of each fungal species was calculated.

\section{Qualitative assay for aflatoxin production}

Aflatoxin and ochratoxin screening with Coconut Agar Media (CAM) was used in the experiment (Davis et al. 1987). $250 \mathrm{~mL}$ of coconut cream (Sainsbury's, UK) was mixed with $250 \mathrm{~mL}$ of deionised water using a heated stirrer at $75^{\circ} \mathrm{C}$. $10 \mathrm{~g}$ of Technical Agar No.3 (Sigma Aldrich, USA) and $0.16 \mathrm{~g}$ of chloramphenicol were added to the solution. The medium was autoclaved and poured into $9 \mathrm{~cm}$ Petri plates. After cooling at room temperature, the plates were inoculated with a spore suspension of six isolates each of $A$. flavus $\left(\mathrm{AFg}_{1}, \mathrm{AFg}_{2}, \mathrm{AFg}_{3}, \mathrm{AFt}_{1}, \mathrm{AFt}_{2}\right.$ and $\mathrm{AFt}_{3}$ and A. niger $\left(\mathrm{ANg}_{1}, \mathrm{ANg}_{2^{\prime}} \mathrm{ANg}_{3^{\prime}} \mathrm{ANt}_{1^{\prime}} \mathrm{ANt}_{2}\right.$ and $\left.\mathrm{ANt}_{3}\right)$ with a sterile loop. The inoculated plates were incubated at $25^{\circ} \mathrm{C}$ for 7 days. They were examined for orange-yellow pigmentation and at the reverse side the presence or absence of a blue fluorescent ring under UV light, characteristic of aflatoxin and ochratoxin-producing strains (Lin \& Dianese 1976). For comparison, Aspergillus flavus strain (NRRL 3357) and Aspergillus carbonarius (Carbo 197) were used as control.

\section{Quantitative analysis using High Performance Liquid Chromatography (HPLC)}

Aspergillus flavus isolates $\left(\mathrm{AFg}_{1}, \mathrm{AFg}_{2}, \mathrm{AFg}_{3}, \mathrm{AFt}_{1^{\prime}}\right.$ $\mathrm{AFt}_{2}$ and $\mathrm{AFt}_{3}$ ) were subsequently cultured on a mycotoxin conducive Yeast Extract Sucrose agar medium (YES, Oxoid Ltd., UK) for 10 days. Six discs (4 mm diameter) of each fungal culture were placed in $2 \mathrm{~mL}$ volume safe-lock Eppendorf tubes. The weight of Eppendorf and Eppendorf + agar was taken. Aflatoxin was extracted with $0.75 \mathrm{~mL}$ of $100 \%$ methanol by shaking well for $1 \mathrm{~h}$ at 150 $\mathrm{rpm}$ at $25^{\circ} \mathrm{C}$. The methanol extract was transferred to Eppendorf tubes and dried at $45^{\circ} \mathrm{C}$ in a speed vacuum. Samples were dissolved in $0.5 \mathrm{~mL}$ of methanol:water (50:50), vortexed and filtered with $0.22 \mu \mathrm{m}$ filter (Kromega, Jaytee Biosciences Ltd., UK) into sylinazed HPLC vials using $1 \mathrm{~mL}$ syringes (Terumo Medical Corporation, UK). The HPLC equipment used was an Agilent 1200 Series system (Agilent, Berkshire, UK) with a fluorescence detector (FLD)
(Millipore Waters, Corporation Massachusetts, USA), at excitation and emission wavelengths of 365 and $440 \mathrm{~nm}$ respectively, and flow rate of the mobile phase (methanol/water/acetonitrile, $30 / 60 / 15, \mathrm{v} / \mathrm{v} / \mathrm{v}$ ) of $1 \mathrm{~mL} / \mathrm{min}$ for a running time of $12 \mathrm{~min}$. Separation was achieved through the use of a $\mathrm{C}_{18}$ column (Poroshell 120 EC-C18 $4.6 \times$ $100 \mathrm{~mm}, 2.7 \mu \mathrm{m})$ preceded by a Phenomenex Gemini $C_{18} 3 \mathrm{~mm}, 3 \mu \mathrm{m}$ guard cartridge) (Castano et al. 2017).

\section{Results and discussion}

\section{Occurrence of fungal flora}

Aspergillus spp were isolated from ginger and turmeric samples in both media and methods at varying degrees. In direct planting method, Aspergillus spp accounted for between 23\% (MEA) (Fig. 1a) and 43\% (DG 18) (Fig. 1b) in ginger and 68\% (MEA) (Fig. 2a) and 64\% (DG18) (Fig. $2 \mathrm{~b}$ ) in turmeric of the total fungi species isolated. A. flavus and A. niger dominated in MEA medium in both samples accounting for more that $30 \%$ when the samples were surface sterilised. Six isolates each of $A$. flavus $\left(\mathrm{AFg}_{1^{\prime}}, \mathrm{AFg}_{2,} \mathrm{AFg}_{3}, \mathrm{AFt}_{1^{\prime}}\right.$ $\mathrm{AFt}_{2}$ and $\left.\mathrm{AFt}_{3}\right)$ and $A$. niger $\left(\mathrm{ANg}_{1}, \mathrm{ANg}_{2^{\prime}} \mathrm{ANg}_{3^{\prime}}\right.$ $\mathrm{ANt}_{1}, \mathrm{ANt}_{2}$ and $\mathrm{ANt}_{3}$ ) were subsequently purified and used for further analysis. This included three each from ginger and turmeric. The $\mathrm{AFg}$ and $\mathrm{ANg}$ and AFt and AN $t$ designate represented A. flavus and $A$. niger isolates from ginger and turmeric, respectively. $A$. tamarii and $A$. terreus appeared to have grown better on DG 18 medium especially in turmeric samples. Growth of $A$. terreus was not observed in ginger when the samples were surface sterilised as it seems to be a secondary infection. Other fungal species isolated from both spices in both media included; Alternaria sp, Fusarium sp, Mucor sp, Penicillium sp, Rhizopus sp and Eurotium sp (Fig. 1 \& 2). In general Fusarium and Penicillium spp were the dominant fungal flora in both spices. Rawat et al. (2014) have reported some of these fungi in stored spices. They observed that A. niger, A. flavus, Mucor and Rhizopus species were the dominant mycoflora. Jeswal \& Kumar $(2014 ; 2015)$ also reported the occurrence of F. oxysporum and Aspergillus spp in both stored ginger and turmeric samples with ginger having high aflatoxin contaminations. In their study, A. tamarii was only confined to red chilli samples, unlike in the present study where 

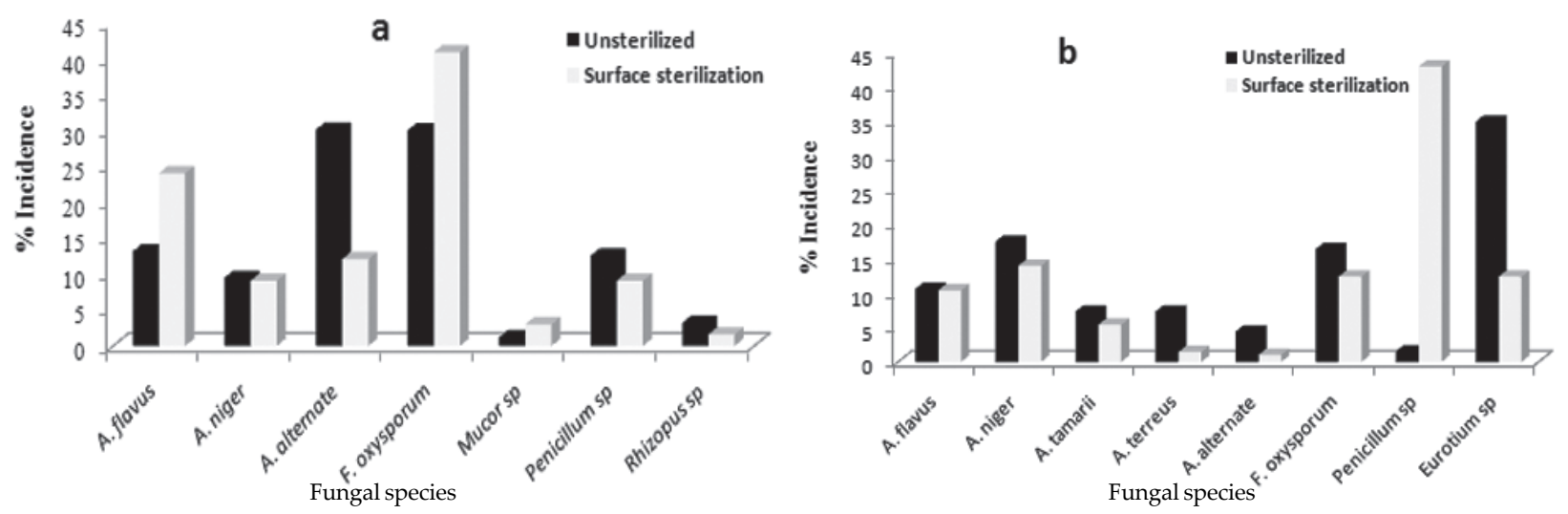

Fig. 1. Fungal species isolated from unsterilized and surface sterilized ginger samples in (a) MEA and (b) DG 18 media.
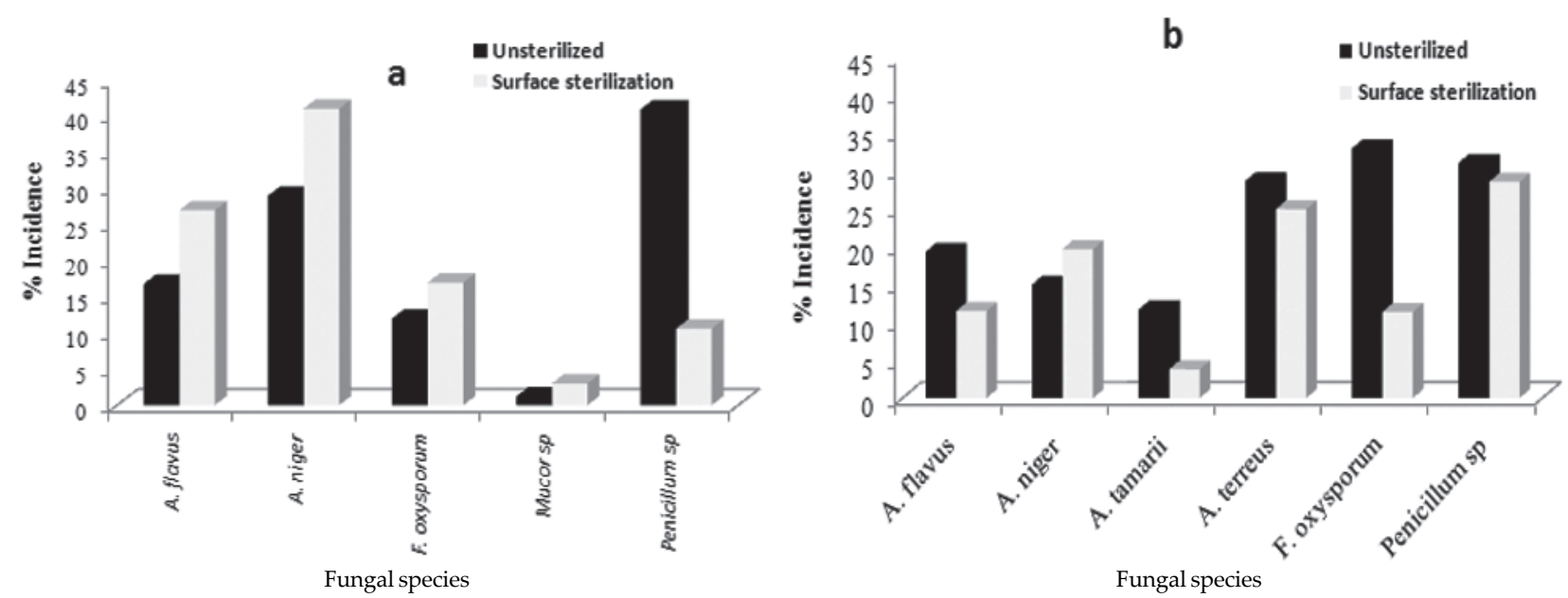

Fig. 2. Fungal species isolated from unsterilized and surface sterilized turmeric samples in (a) MEA and (b) DG 18 media.

these organisms were found in both ginger and turmeric. This may be the first report of the occurrence of $A$. terreus and $A$. tamarii in ginger and turmeric in Southern Nigeria.

Toxin production by isolates of $A$. flavus

Results of tests with CAM and YES media for HPLC analysis are presented in Tables $1 \& 2$. The A. flavus isolates $\left(\mathrm{AFg}_{1}, \mathrm{AFg}_{3^{\prime}} \mathrm{AFt}_{1}\right.$ and $\left.\mathrm{AFt}_{3}\right)$ produced AFs both qualitatively and quantitatively. It was necessary to carry out quantitative analyses on $A$. flavus isolates as the CAM media may not be able to identify isolates which were very low producers of AFs (Lin \& Dianese 1976). None of the A. niger isolates produced the orange-yellow pigmentation or blue fluorescence on the reverse side of the colony under UV light, suggesting that they may be $A$. niger (uniseriate) or low toxin-producers, although this was not confirmed quantitatively. Sultan \& Magan (2010) found isolates of $A$. niger from Egyptian peanuts to be non OTA producers and this is in line with the results of the present study. However, A. niger, A. ochraceus and $A$. carbonarius, have been reported to produce ochratoxin A in green coffee (Taniwaki et al. 1999). In the control, $A$. flavus NRRL 3357 and $A$. carbonarius Carbo 197, both rapid growers and relatively potent aflatoxin and ochratoxin producers respectively, had blue fluorescence produced on the reverse side of the colonies in 2 days. The other aflatoxin producers $\left(\mathrm{AFg}_{1}, \mathrm{AFg}_{3^{\prime}}\right.$ $\mathrm{AFt}_{1}$ and $\mathrm{AFt}_{3}$ ) took 4-5 days to produce a blue fluorescent ring surrounding the colony. At incubation longer than 7 days, it was difficult to evaluate because mycelial growth reached the 
Table 1. Production of orange-yellow pigmentation and blue fluorescence by isolates of $A$. flavus and $A$. niger on coconut agar medium (CAM).

\begin{tabular}{lcc}
\hline $\begin{array}{l}\text { A. Flavus } \\
\text { isolate }\end{array}$ & $\begin{array}{c}\text { Orange- } \\
\text { yellow } \\
\text { Pigmentation }\end{array}$ & $\begin{array}{c}\text { Blue } \\
\text { fluorescence }\end{array}$ \\
\hline $\mathrm{AFg}_{1}$ & + & + \\
$\mathrm{AFg}_{2}$ & - & - \\
$\mathrm{AFg}_{3}$ & + & + \\
$\mathrm{AFt}_{1}$ & + & + \\
$\mathrm{AFt}_{2}$ & - & - \\
$\mathrm{AFt}_{3}$ & + & + \\
$\mathrm{ANg}_{1}$ & - & - \\
$\mathrm{ANg}_{2}$ & - & - \\
$\mathrm{ANg}_{3}$ & - & - \\
$\mathrm{ANt}_{1}$ & - & - \\
$\mathrm{ANt}_{2}$ & - & + \\
$\mathrm{ANt}_{3}$ & - & + \\
$\mathrm{NRRL}_{3357}$ & + & + \\
$\mathrm{Carbo}_{197}$ & + & + \\
\hline
\end{tabular}

$+=$ presence; $-=$ absence; $\mathrm{AFg}=A$. flavus isolate from ginger; $\mathrm{AFt}=A$. flavus isolate from turmeric; $\mathrm{ANg}=A$. niger isolate from ginger; $\mathrm{ANt}=A$. niger isolate from turmeric.

Table 2. Production of aflatoxin $B_{1}$ and $B_{2}$ by isolates of $A$. flavus on Yeast Extract Sucrose (YES) medium

\begin{tabular}{lcc}
\hline A. flavus & \multicolumn{2}{c}{ Toxin in $\mathrm{ng} \mathrm{g}^{-1}$ of agar } \\
\cline { 2 - 3 } & $\mathrm{AFB}_{1}$ & $\mathrm{AFB}_{2}$ \\
\hline $\mathrm{AFg}_{1}$ & 192 & 55 \\
$\mathrm{AFg}_{2}$ & - & - \\
$\mathrm{AFg}_{3}$ & 551 & 119 \\
$\mathrm{AFt}_{1}$ & 114 & 22 \\
$\mathrm{AFt}_{2}$ & - & - \\
$\mathrm{AFt}_{3}$ & 373 & 547 \\
\hline $\mathrm{AFg}$ &
\end{tabular}

$\mathrm{AFg}=A$. flavus isolate from ginger; $\mathrm{AFt}=A$. flavus isolate from turmeric; - = no toxin produced. margin of the plate and made the blue fluorescence invisible and this was the case with the other isolates. 3-5 days was ideal for the evaluation of the plates, and a plate was assumed to be negative when on the reverse side, a thin blue fluorescent ring just external to the colony was absent.

According to Lin \& Dianese (1976), the production of an orange-yellow pigmentation of the mycelium prior to the appearance of blue fluorescence is an estimator of toxin producing isolates. This was used to estimate the aflatoxinproducing ability in their study without the use of a UV lamp. The present study corroborated this, as all the isolates that produced orangeyellow pigmentation also produced blue fluorescence and was later confirmed to be toxin producers. Thus, it was found that the production of orange-yellow pigment seemed to be a reliable indicator of aflatoxin-production contrasting the works of Davis et al. (1987). Davis et al. (1987) in their work found that some isolates which produced the orange-yellow pigment did not produce blue fluorescence and concluded that the production of orange-yellow pigmentation might not be a reliable indicator of aflatoxinproducing ability. Coconut cream was satisfactory in supporting growth and blue fluorescence when used as medium. These products contained appreciable levels of added sugar; emulsifier: mono and diglycerides of fatty acids and stabilizers. A. flavus isolates grew extremely well on the YES medium and chemical analysis confirmed the production of aflatoxin (Table 2). The maximum accumulation of $\mathrm{AFB}_{1}$ and $\mathrm{AFB}_{2}$ (551 and $549 \mathrm{ng} \mathrm{g}^{-1}$, respectively) was observed in isolate $\mathrm{AFg}_{3}$ and $\mathrm{AFt}_{3^{\prime}}$ respectively, while the least was observed in $\mathrm{AFt}_{1}$ (114 and 22 $\mathrm{ng} \mathrm{g}^{-1}$, respectively). The most commonly found aflatoxin in food and food products is $\mathrm{AFB}_{1^{\prime}}$ followed by $\mathrm{AFB}_{2^{\prime}} \mathrm{AFG}_{1}$ and $\mathrm{AFG}_{2}$ (Castano et al. 2017) and EU has set legislative limit for total $\mathrm{AFs} / \mathrm{AFB}_{1}$ in ginger, turmeric and other spices. For ginger and turmeric, the legislative limit is 5 $\mu \mathrm{g} \mathrm{kg}^{-1}$ and $10 \mu \mathrm{g} \mathrm{kg}^{-1}$ for $\mathrm{AFB}_{1}$ and total AFs, respectively. The amount of $\mathrm{AFB}_{1}$ produced by these isolates in YES medium exceeded the EU limits and these doses raise safety concerns for ginger and turmeric and emphasize the possible hazardous nature of such contamination in the study area. 
In conclusion, the current study demonstrated that ginger and turmeric consumed in the Niger Delta region of Nigeria supported the growth of toxic fungi. All the samples were contaminated with Aspergillus spp and most of isolated A. flavus were aflatoxin producing. The use of CAM media proved to be a rapid and simple method to qualify AF-producing A. flavus isolates. This may be a first report of $A$. terreus and $A$. tamarii occurrence in ginger and turmeric from the Niger Delta region of Nigeria. Poor post-harvest handling and storage of ginger and turmeric in the Niger Delta of Nigeria could increase the risk of contamination with aflatoxins above the legislative limits.

\section{Acknowledgement}

This study was funded by Commonwealth Scholarship Commission, UK and the University of Port Harcourt, Nigeria.

\section{References}

Bakht J, Azra \& Shafi M 2012 Antimicrobial activity of Nicotiana tobaccum using different solvent extracts. Pak. J. Bot. 44: 459-463.

Bakht J, Khan S \& Shafi M 2013 Antimicrobial potential of fresh Allium cepa against gram positive and gram negative bacteria and fungi. Pak. J. Bot. 45: 1-6.

Castano S M, Medina A \& Magan N 2017 Comparison of dry matter losses and aflatoxin $\mathrm{B}_{1}$ contamination of paddy and brown rice stored naturally or after inoculation with Aspergillus flavus at different environmental conditions. J. Stored Prod. Res. 73: 47-53.

Chaudhary A S, Sachan S K \& Singh R L 2006 Studies on varietal performance of turmeric (Curcuma longa L.). Indian J. Crop Sci. 1: 189-190.

Chen J C, Huang L, Shiblu W \& Hsiang C 2007 Ginger and its bioactive component in inhibiting enterotoxigenic escherichia, coli-heat-labile enterotoxin-induced diarrhea in mice. J. Agri. Food Chem. 55: 8390-8397.

Davis N D, Iyer S K \& Diener U L 1987 Improved Method of Screening for Aflatoxin with a Coconut Agar Medium. Appl. Environ. Microbiol. 53: 1593-1595.

Ernest E \& Pittler M H 2008 Efficacy of Ginger for nausea and vomiting: A systematic review of randomized clinical trial. Br. J. Anesthetcs
84: 367-371.

European Commission 2006 Commission Regulation (EC) No. 1881/2006 of 19 December 2006 setting maximum levels for certain contaminants in foodstuffs. Official J. Eur. Union L, 364: 5-24.

European Commission 2010 Regulation (EC) No 165/ 2010 of 26 February 2010 amending Regulation (EC) No 1881/2006 setting maximum levels for certain contaminants in foodstuffs as regards aflatoxins.

FAO/WHO 2017 Evaluation of certain contaminants in food. WHO technical report series; no. 1002.

Jeswal P \& Kumar D 2014 Toxigenic mycofloral association and mycotoxins contamination in turmeric, coriander and red chilli and risk assessment of its effects. American J. Biol. Chem. Pharmaceutical Sci. 2: 10.17.

Jeswal P \& Kumar D 2015 Mycobiota and natural incidence of aflatoxins, ochratoxin A, and citrinin in Indian spices confirmed by LC-MS/ MS. Int. J. Microbiol. 2015: 1-8.

Karim M R, Abedul H, Khairul A, Nurshad A S, Kazi A, Zahangir H, Ekhtear F, Abul A, Anwarul H \& Seiichiro H K 2010 Protective effects of the dietary supplementation of turmeric (Curcuma longa L.) on sodium arsenite induced biochemical perturbation in mice. Bangladesh. Med Res. Council Bull. 36: 82-88.

Kim J S, Park S, Hyewon Y \& Jaetteon S 2008 Cytotoxic components from the dried rhizomes of Zingiber officinale Roscoe. Arch. Pharmacal. Res. 31: 415-418.

Lin M T \& Dianese J C 1976 A coconut-agar medium for rapid detection of aflatoxin production by Aspergillus spp. Phytopathol. 66: 1466-1469.

Liu Y \& Wu F 2010 Global burden of aflatoxininduced hepatocellular carcinoma: A risk assessment. Environ. Health Perspectives 118: 818-824.

Magan N, Medina A \& Aldred D 2011 Possible climate change effects on mycotoxin contamination of food crops pre- and postharvest. Plant Pathol. 60: 150-163.

Marin S, Sanchis V, Saenz J, Ramos A, Vinas I \& Magan N 1998 Ecological determinants for germination and growth of some Aspergillus and Penicillium spp. from maize grain. J. Appl. Microbiol. 84: 25-36. 
Nicholson P, Gosman N, Draeger R, Thomsett M, Chandler E \& Steed A 2007 The Fusarium head blight pathosystem: Status and knowledge of its components. Dev. Plant Br. 12: 23-36.

Olojede A O, Nwokocha C C, Akinpelu A O \& Dalyop T 2009 Effect of variety, rhizome and seed bed types on yield of turmeric (Curcuma longa $\mathrm{L}$ ) under a Humid Tropical Agro-Ecol. Adv. Biol. Res. 3: 40-42.

Pitt J I \& Hocking A D 2009 Fungi and food spoilage, $3^{\text {rd }}$ Edition, Spinger, Dordrecht Heidelberg, New York.

Rawat A, Mahajan S, Gupta A, Agnihotri K, Wahi N \& Sharm R 2014 Detection of toxigenic fungi and mycotoxins in some stored medicinal plant samples. Int. J. Appl. Sci. Biotech. 2: 211-216.

Schmidt-Heydt M, Rufer G E, Abdel-Hadi A, Magan N \& Geisen R 2010 The production of aflatoxin
$\mathrm{B}_{1}$ or $\mathrm{G}_{1}$ by Aspergillus parasiticus at various combinations of temperature and water activity is related to the ratio of aflS and aflR expression. Mycotoxin Res. 26: 241-246.

Sherman P W \& Billing J 1999 Darwinian gastronomy: why we use spices: spices taste good because they are good for us. Bio Sci. 49: 453-463.

Singletary K 2010 Turmeric: An overview of potential health benefits. Nutrition Today. 45: 216-225.

Sultan Y \& Magan N 2010 Mycotoxigenic fungi in peanuts from different geographic regions of Egypt. Mycotoxin Res. 26: 133-140.

Taniwaki M H, Pitt J I, Urbano G R, Teixeira A A \& Leitao M F F 1999 Fungi producing ochratoxin A in coffee. In proceedings of the 18 ASIC Coffee Conference (p.239-247), Helsinki, Finland. 